\title{
As contribuições de Paulo Freire para o Design da Informação
}

\section{Paulo Freire's contributions to Information Design}

Giovanna da Silva Machado, Letícia Bito Maynart, Maria Luiza Santos do Amaral, Bernardo Minozzo, Marco Mazzarotto

Paulo Freire, design da informação, design social

Superar as opressões por meio da visão crítica e da ação dialógica são ideias centrais da filosofia de Paulo Freire. Inspirado por essa premissa, este artigo apresenta os resultados de uma revisão bibliográfica sistemática que buscou identificar as contribuições do autor para o Design da Informação. Como resultado, percebe-se que o potencial crítico de sua obra ainda é pouco explorado pela literatura nesta área do design.

Paulo Freire, information design, social design

Overcoming oppressions through critical view and dialogical action are central ideas in Paulo Freire's philosophy. Inspired by this premise, this article presents results of a Systematic Literature Review on the author's contributions to Information Design. The conclusion is that the critical potential of his work is still mildly explored by literature in this area of design.

\section{Introdução}

O cerne do pensamento de Paulo Freire (1970) é a mudança social através da educação libertadora e da ação dialógica, possibilitando aos oprimidos o reconhecimento de sua humanidade e a luta coletiva contra estruturas opressivas. Entretanto, isso não se limita ao campo pedagógico, pois o diálogo crítico, a construção coletiva do conhecimento e a superação das opressões são deveres ontológicos de qualquer profissional - designers inclusos - que devem se ver como cidadãos políticos.

Partindo deste princípio, este trabalho, fruto de um projeto de iniciação científica, buscou contribuições da obra de Freire para o design. Primeiramente, expõe-se neste artigo a presença da filosofia freiriana em trabalhos na área do design como um todo, para, em seguida, investigar por meio de uma revisão bibliográfica sistemática a presença dessas contribuições no campo específico do Design da Informação (DI). Como resultado, evidencia-se que Freire é pouco utilizado para refletir sobre o DI, tendo seu uso normalmente limitado a obras que abordam questões educacionais, sem aproveitar tais ideias para pensar os processos de design. 


\section{Paulo Freire e Design}

Freire (1970) descreve a sociedade em uma contradição opressor-oprimido e, por conseguinte, estabelece a necessidade de transformação social, entendida como um processo comunitário que parte da conscientização, quando opressor e oprimido entendem-se como tal. Sendo ele educador, desenvolve sob perspectivas pedagógicas, mecanismos para suprir essa carência.

Freire critica a ausência de uma educação libertadora e defende a necessidade de extrapolar as fronteiras pedagógicas, tanto para desenvolvimento pessoal quanto para a prática de liberdade. Enquadra a educação como postura: na qual o processo educacional exige respeito, humildade, diálogo e reflexão, pois aprender é uma construção crítica, participativa e libertadora.

Conceitos freirianos podem ser trazidos para o design. Quando afirma que "o mundo não é, o mundo está sendo", Freire (1997) defende que a realidade é transformável e só acontecerá através da práxis - unidade dialética entre ação transformadora e reflexão crítica. Carvalho (2018) articula que "o design fornece as ligações tangíveis e inteligíveis para a comunicação e a ação", devendo assim explorar o conceito de práxis.

Canônica et al. (2014) expõem que o design social enfatiza a autonomia do indivíduo através do diálogo e da conscientização para a prática libertadora. Citando Freire, os autores defendem a importância da prática dialógica, onde "os sujeitos se encontram em colaboração para a transformação do mundo". Similarmente, "o design participativo busca, com as pessoas, criar soluções para seus problemas", configurando também uma construção coletiva do saber.

Gonzatto e van Amstel (2017) destacam que a superação da opressão não depende de heróis, mas dos oprimidos e das ferramentas que possuem para a libertação. Para Freire (1970), "ninguém liberta ninguém, ninguém se liberta sozinho: [as pessoas] se libertam em comunhão". Segundo Carvalho (2018), a educação formal não confere ao designer autoridade, mas responsabilidade. Assim sendo, Canônica et al. (2014) indicam que cabe a ele o papel de facilitador-educador, mediando a aprendizagem e a troca de saberes.

Abbonizio e Fontoura (2008) apontam que a interação designer-indivíduos adquire características que, para além do domínio técnico, estão relacionadas às atitudes e comportamentos frente a dada situação. Portanto, a abordagem do designer precisa permitir que o oprimido pense em soluções, inserindo o indivíduo e o conjunto de referências que fazem parte do seu universo: contexto social, significados, valores, conceitos e definições.

Carvalho (2018) ressalta que, na origem do design participativo, a orientação era política e crítica. Entretanto, a participação foi cooptada para servir a intuitos neoliberais. O foco se voltou para o "como" e não ao "porquê". Por isso, faz-se mister que tais valores sejam resgatados, contribuindo para um design que se posicione e de fato promova a mudança social.

\section{Método}

A pesquisa foi conduzida a partir de uma Revisão Bibliográfica Sistemática através do periódico InfoDesign - Revista Brasileira de Design da Informação, dos anais do Congresso Internacional 
de Design da Informação (CIDI) e da plataforma "Google Acadêmico", buscando trabalhos em português pelas strings "Design da Informação AND Paulo Freire" e "Design de Informação AND Paulo Freire", atingindo o resultado bruto de 184 publicações. Estes foram reduzidos a 24, após leitura que excluiu artigos em que os termos estavam em notas de rodapé, agradecimentos ou nomes de entidades. Por fim, após verificação aprofundada, foram excluídos 18 artigos por abordarem vagamente um dos temas. As seis publicações finais foram fichadas e analisadas na planilha da figura 1, alcançando assim o resultado apresentado.

Figura 1: Planilha para análise dos trabalhos

\begin{tabular}{|c|c|c|c|c|c|c|c|c|c|c|}
\hline Nome do trabalho & Fichado? & Autores & Ano & Tipo & $\begin{array}{c}\text { Escala } \\
\text { Paulo Freire }\end{array}$ & $\begin{array}{l}\text { Obs. escala } \\
\text { Paulo Freire }\end{array}$ & $\begin{array}{l}\text { Escala Design } \\
\text { da Informaçäo }\end{array}$ & $\begin{array}{l}\text { Obs. escala } \\
\text { Design da } \\
\text { informação }\end{array}$ & \begin{tabular}{|c|} 
Relaçāoo \\
Freire e \\
Design
\end{tabular} & $\begin{array}{l}\text { Obs. relação entre } \\
\text { Freire e design }\end{array}$ \\
\hline $\begin{array}{l}\text { Usuârios e produção da } \\
\text { existência: contribuiçōes } \\
\text { de Álvaro Vieira Pinto e } \\
\text { Paulo Freire à interação } \\
\text { humano-computador }\end{array}$ & SIM & $\begin{array}{l}\text { Rodrigo Freese } \\
\text { Gonzatto }\end{array}$ & 2018 & Tese & $\begin{array}{l}\text { Freire é base } \\
\text { principal }\end{array}$ & $\begin{array}{l}\text { Segundo o autor, a } \\
\text { base principal e } \\
\text { Álvaro Vieira Pinto, } \\
\text { mas o diálogo com } \\
\text { conceitos de Freire } \\
\text { se dá em todo o } \\
\text { trabalho }\end{array}$ & $\begin{array}{l}\text { Design da } \\
\text { informacăâ faz } \\
\text { parte da base } \\
\text { teórica mas não } \\
\text { e o mais } \\
\text { importante }\end{array}$ & $\begin{array}{l}\text { O autor considera } \\
\text { o Design da } \\
\text { Informaçấo como } \\
\text { área correlata da } \\
\text { IHC }\end{array}$ & Alta & $\begin{array}{l}\text { Freire entra como base } \\
\text { teórica para } \\
\text { problematizar conceitos } \\
\text { da IHC (do design de } \\
\text { informação, por } \\
\text { consequência) }\end{array}$ \\
\hline $\begin{array}{l}\text { Oensino de modelagem } \\
\text { do vestuário na } \\
\text { perspectiva do Design da } \\
\text { Informação }\end{array}$ & SIM & $\begin{array}{l}\text { Rita de Cássia } \\
\text { Nunes e Maria Alice } \\
\text { Vasconcelos Rocha }\end{array}$ & 2018 & $\begin{array}{l}\text { Artigo em } \\
\text { periódico }\end{array}$ & $\begin{array}{l}\text { Freire é base } \\
\text { principal }\end{array}$ & & $\begin{array}{l}\text { Design da } \\
\text { informação é o } \\
\text { tipo principal de } \\
\text { design }\end{array}$ & & Baixa & $\begin{array}{l}\text { Faltou incluir a didática } \\
\text { freiriana na ação do } \\
\text { problema. }\end{array}$ \\
\hline $\begin{array}{l}\text { DESIGN/EDUCAÇÃO: a } \\
\text { convivialidade como } \\
\text { território para a discussão } \\
\text { do Design da Informaçâa } \\
\text { como ferramenta de } \\
\text { ensino-aprendizagem } \\
\text { escolar }\end{array}$ & SIM & $\begin{array}{l}\text { Olivia Morim de } \\
\text { Melo }\end{array}$ & 2017 & Dissertaçāo & $\begin{array}{l}\text { Freire faz } \\
\text { parte da base } \\
\text { teorica mas } \\
\text { não é o mais } \\
\text { importante }\end{array}$ & $\begin{array}{l}\text { Freire é usado } \\
\text { como } \\
\text { "comparativo" para } \\
\text { embasar outro } \\
\text { conceito filosófico } \\
\text { de outro autor. }\end{array}$ & $\begin{array}{l}\text { Design da } \\
\text { informaçấ é o } \\
\text { tipo principal de } \\
\text { design }\end{array}$ & $\begin{array}{l}\text { Muito relacionado } \\
\text { à educação. }\end{array}$ & Nenhuma & \\
\hline \begin{tabular}{|l} 
Principios do Design da \\
Informação na Curadoria \\
Digital de Ambientes \\
Virtuais de Aprendizagem \\
sob a perspectiva da \\
Ciência da Informaçāo
\end{tabular} & SIM & Natália Nakano & 2019 & Tese & $\begin{array}{l}\text { Freire faz } \\
\text { parte da base } \\
\text { teórica mas } \\
\text { não é o mais } \\
\text { importante }\end{array}$ & $\begin{array}{l}\text { Freire e base para } \\
\text { um capitulo, seu } \\
\text { trabalho é citado e } \\
\text { relacionado à } \\
\text { educação, no } \\
\text { caso, em } \\
\text { especifico EaD. }\end{array}$ & $\begin{array}{l}\text { Design da } \\
\text { informacăo é o } \\
\text { tipo principal de } \\
\text { design }\end{array}$ & $\begin{array}{l}\text { Está presente na } \\
\text { tese intercalada } \\
\text { ao conceito de } \\
\text { ciência da } \\
\text { informaçâa. }\end{array}$ & Nenhuma & $\begin{array}{l}\text { Não encontrei relação } \\
\text { direta, a interseção e } \\
\text { pautada pela } \\
\text { pedagogia, em relação } \\
\text { a teoria do } \\
\text { conectivismo. }\end{array}$ \\
\hline $\begin{array}{l}\text { A CULTURA VISUAL NA } \\
\text { ESCOLAE OS } \\
\text { PROCESSOS } \\
\text { MEDIADORES DO } \\
\text { DESIGN NA } \\
\text { PERSPECTIVA } \\
\text { FREIRIANA }\end{array}$ & SIM & $\begin{array}{l}\text { Rosileide Guedes } \\
\text { Sant'Ana de Farias } \\
\text { Elizabelle Pereira } \\
\text { Costa }\end{array}$ & 2013 & $\begin{array}{l}\text { Artigo em } \\
\text { congresso }\end{array}$ & $\begin{array}{l}\text { Freire faz } \\
\text { parte da base } \\
\text { teórica mas } \\
\text { não é o mais } \\
\text { importante }\end{array}$ & $\begin{array}{l}\text { Freire é usado } \\
\text { bastante para a } \\
\text { fundamentacao do } \\
\text { artigo em relacao } \\
\text { a educaco, mas } \\
\text { em relacao ao } \\
\text { design nao }\end{array}$ & $\begin{array}{l}\text { Design da } \\
\text { informaçâo é o } \\
\text { tipo principal de } \\
\text { design }\end{array}$ & $\begin{array}{l}\text { Relacionado } \\
\text { totalemente ao } \\
\text { uso educacional }\end{array}$ & Baixa & $\begin{array}{l}\text { Freire é constante em } \\
\text { relação a educacao e o } \\
\text { design da informacao é } \\
\text { inserido para contribuir } \\
\text { com essa educacao } \\
\text { mais dialogica, mas não } \\
\text { há relacoes diretas } \\
\text { entre os dois }\end{array}$ \\
\hline $\begin{array}{l}\text { CONSCIÊNCIAE AÇÃO } \\
\text { EM DESIGN DE } \\
\text { INTERACĀAO: } \\
\text { RECURSOS E PRATICAS } \\
\text { EDUCACIONAIS } \\
\text { ABERTAS PARA O } \\
\text { ESPERANÇAR }\end{array}$ & SIM & $\begin{array}{l}\text { Cláudia Bordin } \\
\text { Rodrigues da Silva }\end{array}$ & 2019 & Tese & $\begin{array}{l}\text { Freire é base } \\
\text { principal }\end{array}$ & & $\begin{array}{l}\text { Design da } \\
\text { informação faz } \\
\text { parte da base } \\
\text { teórica mas não } \\
\text { é o mais } \\
\text { importante }\end{array}$ & $\begin{array}{l}\text { Aborda Design de } \\
\text { interaçãa, mas } \\
\text { trata design de } \\
\text { informação como } \\
\text { área correlata }\end{array}$ & Alta & \\
\hline
\end{tabular}

\section{Resultados e Discussão}

Durante a análise das publicações finais, foram definidos graus de aprofundamento de suas abordagens sobre Paulo Freire e DI: abordagem superficial, quando um dos temas é citado apenas para ilustrar um argumento ou relacionar a um segmento específico e pouco relevante; abordagem mediana, quando o tema é presente, mas não é o mais importante; e abordagem profunda, quando o tema é protagonista da discussão-argumento. Todas as obras com abordagem superficial foram excluídas do estudo.

Foram definidos também graus para as relações entre Freire e DI: nenhuma, quando os temas não são relacionados; baixa, em que a relação é implícita ou interpretativa; média, para relações presentes, mas não exploradas; alta, caso as relações fossem abordadas e desenvolvidas explicitamente. 
Tabela 1: Análise dos resultados da RBS

\begin{tabular}{llll}
\hline Autor (ANO) & Escala DI & $\begin{array}{l}\text { Escala Paulo } \\
\text { Freire }\end{array}$ & $\begin{array}{l}\text { Relação entre DI } \\
\text { e Paulo Freire }\end{array}$ \\
\hline FARIAS e COSTA (2013) & Profunda & Mediana & Baixa \\
MELO (2017) & Profunda & Mediana & Nenhuma \\
NAKANO (2019) & Profunda & Mediana & Nenhuma \\
NUNES e ROCHA (2018) & Profunda & Profunda & Baixa \\
GONZATTO (2018) & $\begin{array}{l}\text { Mediana (Design da } \\
\text { interação é o principal) }\end{array}$ & Profunda & Alta \\
SILVA (2019) & $\begin{array}{l}\text { Mediana (Design da } \\
\text { interação é o principal) }\end{array}$ & Profunda & Alta \\
\hline
\end{tabular}

Como pode ser observado no quadro 1, quatro obras apresentam relação baixa ou inexistente entre DI e Paulo Freire, enquanto duas apresentam nível alto de contribuições freirianas para o design.

Os trabalhos que abordam Freire e DI, mas não trazem nenhuma conexão são pesquisas voltadas à educação. Estas obras utilizam Freire somente no embasamento teórico referente às práticas pedagógicas, sem influenciar questões de design. DI volta-se também para a área educacional, como método de comunicação e desenvolvimento educacional. Novamente, nenhuma relação entre DI e a obra de Freire é explicitada.

Quanto ao segundo grupo, são publicações que abordam profundamente a relação entre princípios freirianos e design. Porém, essa relação é construída principalmente a partir do Design da interação. Mesmo assim, essas obras foram consideradas por considerar Design da Informação como área correlata.

A primeira delas, de Silva (2019), relaciona ideais freirianos com Design de interação, estabelecendo o conceito "esperançar" como foco do desenvolvimento dos projetos, desde o propósito até a análise da interação no objeto de estudo. Clarificando assim conexões entre Freire e Design, tanto no campo de atuação profissional, quanto no caráter social, apontando para a necessidade de acreditar e buscar a superação das opressões.

Já Gonzatto (2018) usa conceitos de Freire para problematizar o termo "usuário" e a produção da existência na Interação Humano-Computador (IHC). O autor aponta que a IHC estabelece uma relação opressiva com o "usuário", pois a divisão de trabalho o distancia dos profissionais, o que corresponde às noções freirianas de "ser menos" e desumanização. O autor propõe que se reconheça "usuários" como protagonistas da produção de interações na área, buscando a superação de tal opressão. 


\section{Conclusões}

O presente artigo, que buscou identificar as contribuições de Paulo Freire para o DI, foi conduzido por uma RBS que identificou seis obras. Destas, apenas duas apontaram relações explícitas entre a visão crítica freiriana e o design, sendo estas obras do campo do design de interação, citando o DI apenas como área correlata. Nas outras quatro obras, o DI é, de fato, a área principal, porém as contribuições de Freire se limitam às questões pedagógicas envolvidas, pouco contribuindo para o pensar e o fazer do design da informação.

Conclui-se que a obra de Freire, mesmo apresentando contribuições para um design crítico, dialógico e libertador, ainda não tem seu potencial plenamente explorado pela área do Design da Informação.

Designers da informação, enquanto envolvidos em projetos de comunicação, precisam assumir a responsabilidade de identificar-se como privilegiados em um sistema opressor estrutural e conscientizar-se de que sua atividade deve ser efetiva. A práxis precisa auxiliar na libertação dos oprimidos, sem reforçar opressões. Incluí-los não como objeto de estudo, mas como participantes ativos. Não limitá-los a meros usuários, mas entendê-los como protagonistas da transformação da realidade. Não mais simples receptores de mensagens e instruções, mas responsáveis por escrever e transformar suas próprias narrativas.

O acesso à ciência e tecnologia demandada pelo fazer design já são instrumentos de manutenção da desigualdade. Portanto, não basta concretizar projetos e realizar mudanças superficiais, requer aprofundamento e transformação político-estrutural. É imprescindível que tanto informação quanto design aproximem-se dos oprimidos e, em uma troca de experiências e sabedoria, provoquem reflexão acerca da realidade em que estão inseridos. O design precisa crescer além dos designers e possibilitar que a comunidade seja não somente um espaço criativo, mas também um espaço político. 


\section{Referências}

Abbonizio, M. E., \& Fontoura, A. M. (2008). Reflexões sobre as intervenções de design no artesanato sob a ótica dos Círculos de Cultura de Paulo Freire. Anais do $8^{\circ}$ Congresso Brasileiro de Pesquisa e Desenvolvimento em Design. 2617-2625. São Paulo.

Canônica, R., Peixe, R. I. P., Santos, A. S., \& Kohls, C. (2014). Relações entre o Design Participativo e Princípios Pedagógicos Freireanos, 1304-1315. Anais do $11^{\circ}$ Congresso Brasileiro de Pesquisa e Desenvolvimento em Design. São Paulo: Blucher.

Carvalho, C. P. (2018). Utopia nas margens: O papel do design na cocriação de alternativas num contexto de exclusão social [Tese]. Universidade do Porto, Portugal.

Farias, R., \& Costa, E. P. (2013) A cultura visual na escola e os processos mediadores do Design na perspectiva freiriana. VIII Colóquio Internacional Paulo Freire. 1-16. Recife.

Freire, P. (1970). Pedagogia do oprimido (17 ed.). Rio de Janeiro: Paz e Terra.

Freire, P. (1997). Pedagogia da Autonomia: saberes necessários à prática educativa. São Paulo: Cortez.

Gonzatto, R. (2018). Usuários e a produção da existência: contribuições de Álvaro Vieira Pinto e Paulo Freire à Interação Humano-Computador [Tese]. UTFPR, Curitiba.

Gonzatto, R. \& van Amstel, F. M. C. (2017). Designing oppressive and libertarian interactions with the conscious body. Proceedings of the XVI Brazilian Symposium on Human Factors in Computing Systems, 22. ACM.

Melo, O. (2017). Design/Educação: a convivialidade como território para a discussão do design da informação como ferramenta de ensino-aprendizagem escolar [Dissertação]. UFPE, Recife.

Nakano, N. (2019). Princípios do design da informação na curadoria digital de ambientes virtuais de aprendizagem sob a perspectiva da ciência da informação. [Tese]. UNESP, Marília.

Nunes, R., \& Rocha, M. A. V. (2018) O ensino de modelagem do vestuário na perspectiva do Design da Informação. Achiote.com - Revista Eletrônica de Moda, 6, 95-112.

Silva, C. B. R. da (2019). Consciência e ação em design de interação: recursos e práticas educacionais abertas para o Esperançar. [Tese]. UTFPR, Curitiba.

\section{Sobre os autores}

Giovanna da S. Machado, Graduanda, UTFPR, Brasil < giovannasmachado@hotmail.com> Letícia B. Maynart, Graduanda, UTFPR, Brasil <leticiabito@gmail.com>

Maria Luiza S. do Amaral, Graduanda, UTFPR, Brasil <malu.amaral06@gmail.com> Bernardo Minozzo, Graduando, UTFPR, Brasil <ber.rmc@gmail.com>

Marco Mazzarotto, Dr., UTFPR e Design \& Opressão, Brasil, <marcomazzarotto@gmail.com> 